\title{
ON THE VOLUMETRIC DETERMINATION OF CARBONIC ACID,
}

Br G. W. Wigner, F.C.S., Read before the Society of Public Analysts, November 15, 1876.

I have used for some time a very simple apparatus for the volumetric determination (in a gaseous state) of the combined Carbornic Acid, in Carbonates. Schiebler's apparatus is, of course, only adapted for those carbonates which produce salts with Hydrochloric or Nitric Acid, which are readily soluble in cold water, and although it is an extremely handy instrument, it is open to several objections, the principal of which are-

That the temperature of the evolved carbonic acid gas, requires to be carefully taken, and this can only be done by taking the temperature of the external air, and allowing the instrument to rest, until the evolved gas has acquired this temperature, and

That the acid solution used to decompose the carbonates, absorbs a proportion, and (according to my experiments) an irregular amount of Carbonic Acid, and finally the scale of the instruments is purely empirical.

Most laboratories are now furnished with the McLeod apparatus, or with some similar efficient apparatus for measuring the volume of gases under known conditions of temperature and pressure, and I have therefore devised a simple apparatus for the

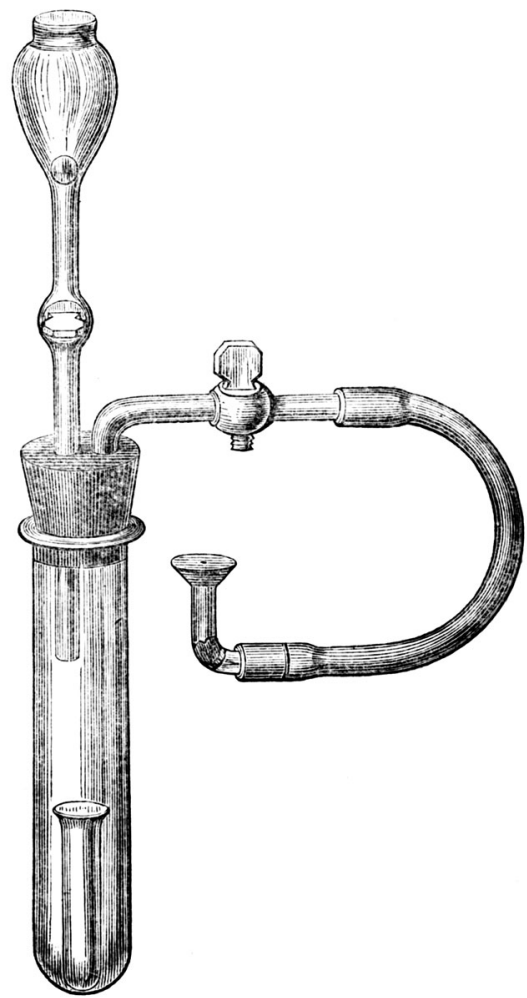
decomposition of carbonates, and the measurement of the gas evolved.

I take a test tube of about 7 inches by 1 inch, and provide it with a good India rubber stopper, bored with two holes. Through one of these holes I pass a tubulated thistle-headed funnel of small size, furnished with a stop-cock, and throught the other a bent piece of small bore glass tubing, also provided with a stopcock.

This bent tube is coupled to the McLeod, or other gas measurement apparatus, by a short length, (say 6 inches) of very stout, small bore, India rubber tube, 1-16in. is large enough for the bore of this.

In the bowl of the thistle funnel, I put a glass marble, and in the interior of the test tube, a smaller test tube of about 2in. + $\frac{3}{8}$, containing the sample to be analysed.

The apparatus is shown complete in the accompanying sketch.

The process is as follows:-

The tubes of the McLeod apparatus are filled with mercury, as if for an ordinary gas analysis, and the stopcocks closed. The sample, (say 25 grains of carbonate of lead) is weighed and transferred to the smallest tube, and about half-an-ounce of distilled water is poured into the large test tube. The small tube is then carefully dropped in, taking care that its mouth is above the level of the water in the 
large tube; the stopper, into which the funnel and bent tube have been inserted is then carefully put in place, and the whole held in a slightly oblique position in a retort stand clamp, on the ordinary rising table of the McLeod apparatus; the India rubber tube is then coupled up to the facets of the measuring tube of the McLeod apparatus. If the stopcocks on the bent tube, and on the funnel are opened for a moment, any excess of air in the India rubber tube is liberated.

The stopeock on the bent tube is now closed, and the mercury in the measuring tube of the McLeod apparatus allowed to fall, so as to produce a vacuum.

The stopcock on the funnel remains open, and a lamp is applied to the bottom of the test tube, until the water boils briskly when distilled water is poured into the funnel and kept from running into the test tube by the pressure of steam generated by the ebullition of the water; the boiling is continued until the steam escaping through the funnel and under the glass marble, all condenses, showing that the tube is filled with pure steam. The lamp is now withdrawn, and the stopcock instantly closed. This is not difficult, as it is three or four seconds before the water in the funnel begins to draw back.

Meanwhile, a portion of dilute nitric acid has been boiled on another burner, and is poured into the funnel. I prefer not to use much more than is necessary for the liberator of the carbonic acid present. The stopcock on the bent tube, and the stopcock on the measuring tube of the McLeod apparatus are opened, and then the stopcock on the funnel is cautiously opened. The hot acid, of course, immediately runs in, and the only precaution necessary, is to avoid liberating the gas too quickly.

When the test tube is about two-thirds full and all effervescence has ceased $I$ again boil the solution in the tube, and then, still maintaining a partial vacuum, by means of the mercury, fill the tube compietely, through the funnel with boiling distilled water, until every bubble of air is driven into the measuring tube of the McLeod.

The stopcock on the bent tube is then shut and the mercury in the pressure tube and the measuring tube of the McLeod brought to the same level. This brings the internal pressure of the air on the short india rubber connecting tube to the atmospheric pressure, and as its volume does not exceed 1c.c. the correction for its temperature may be safe]y omitted.

The gas is then measured in the ordinary way, and its volume calculated to weight and per centage.

I find that it is easy to make four determinations of carbonic acid per hour by this apparatus, and the accuracy of the results is very great.

The following are repeat analyses of commercial white lead, taken at random from some hundreds which I have tabulated, and fairly represent the character of the results, since they include the errors incident to determination of temperature, and barometric pressure, as well as those of mere manipulations in the apparatus.

\begin{tabular}{|c|c|c|c|c|c|c|}
\hline \multirow{9}{*}{$\begin{array}{l}\text { On } 25 \text { grains } \\
\text { in each case. }\end{array}$} & \multicolumn{3}{|c|}{ Ist determination $\mathrm{CO}_{2}$} & & $12 \cdot 222$ & per cent. \\
\hline & 2nd & $"$ & $\mu$ & & $12 \cdot 274$ & 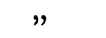 \\
\hline & Ist & 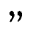 & $"$ & 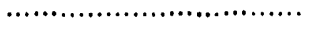 & $13 \cdot 836$ & $"$ \\
\hline & $2 \mathrm{na}$ & $"$ & $"$ & 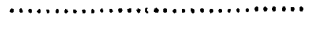 & 13807 & $n$ \\
\hline & lst & $"$ & $"$ & 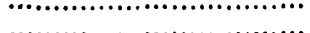 & 10.324 & $\because$ \\
\hline & 1st & $"$ & $"$ & and & $13 \cdot 228$ & $"$ \\
\hline & 2nd & $"$ & $"$ & (1) & $13 \cdot 212$ & $"$ \\
\hline & lst & $"$ & $"$ & 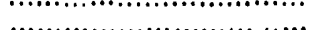 & $11 \cdot 707$ & $"$ \\
\hline & $2 n d$ & 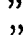 & $"$ & 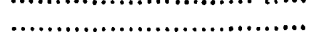 & 11.703 & ", \\
\hline
\end{tabular}

In 6 determinations in different weights of calc. spar. the results varied from 43.83 per cent., to 43.92 per cent., as against 44 per cent. theoretical. Assuming the calc. spar. to have been absolutely pure, the loss of carbonic acid only amounted to an average of 10 per cent., 5 grains being about the average quantity used for the analysis. 